\title{
A INTEligênCIA dos Futuros Contingentes: INTERROGANDO G. W. LEIBNIZ SOBRE DEUS E A VERDADE ${ }^{1}$
}

\author{
Paulo Renato Jesus ${ }^{2}$
}

RESUMO: A presente investigação questiona a essência teo-lógica dos futuros contingentes. Para o efeito, analisa-se, primeiramente, a argumentação segundo a qual, sob certas condiçóes lógicas, teológicas, ontológicas e cosmológicas antinecessitantes, detetadas por G. W. Leibniz (conciliando a posição de St. Agostinho com a de L. Molina e W. Ockham), a abertura contingente do futuro parece ser compatível com o regime das "verdades contingentes pré-determinadas", regime enquadrado teologicamente pelo princípio do "futuro melhor" ou do "único futuro verdadeiro". No entanto, os futuros contingentes incitam, com e contra Aristóteles, ao desenvolvimento de uma lógica temporal e plurivalente, ao modo de J. Łukasiewicz ou A. Prior. Essa lógica garante a abertura do futuro sem o oneroso custo metafísico da adesáo a uma teo-lógica omnideterminante. A crítica do determinismo lógico, daí resultante, afigura-se mais coadunável com as condiçóes pós-metafísicas inerentes à episteme agnóstica contemporânea, mas, nesse caso, a abertura do futuro implicaria uma profunda redefiniçãoo das próprias ideias e funçóes de "Deus", "matéria", "história" e "verdade".

PALAVRAS-CHAVE: Leibniz. Futuros contingentes. Teodiceia. Temporalidade.

\section{Introduçáo: a InTELIGÊNCIA COMo ReGiäo dos PossíVEIS}

Théodore entrant dans cet appartement suprême, se trouva ravi en extase; il lui fallut le secours de la déesse; une goutte d'une liqueur divine le remit. Il ne se sentait pas de joie. Nous sommes dans le vrai monde actuel, dit la déesse, et vous y êtes à la source du bonheur. (LEIBNIZ, Essais de Théodicée, \$. 416 ; GP VI, p. 364).

Il est vrai qu’après avoir concentré en Dieu la totalité du réel, il leur [à Spinoza et Leibniz] devenait difficile de passer de Dieu aux choses, de l'éternité au temps. [...]

\footnotetext{
${ }^{1}$ Esta pesquisa sobre temporalidade insere-se nos Projetos "Poetics of selfhood: Memory, imagination, and narrativity" (PTDC/MHC-FIL/4203/2012) e "Being-in-Stories: The Embodied Poetics of Selfhood" (95899/2013), ambos financiados pela Fundação para a Ciência e Tecnologia (Portugal). http://dx.doi.org/10.1590/S0101-31732016000100002

${ }^{2}$ Centro de Filosofia da Universidade de Lisboa, Portugal. E-mail: paulorenatus@gmail.com
} 
[Ils] supposent toute faite une Science une et complète, avec laquelle coïnciderait tout ce que le sensible contient de réalité. (BERGSON, 1941, p. 351 e 353$)$.

Desde o livro IX do De interpretatione (19 9-35) de Aristóteles (1995, p. 29-30) que os futuros contingentes obrigam a lógica a pensar os seus próprios limites, questionando o caráter lógico ou alógico do inatual, assim como a relação diferencial entre a modalidade e a temporalidade. "Necessariamente, amanhã, haverá ou não haverá uma batalha naval”, $(\mathrm{p} \vee \neg \mathrm{p})$ : o que se segue? Se, segundo o princípio de não-contradição, a disjunção é necessária, então tertium non datur: somente um dos contrários será realidade ou verdade amanhã. Porém, da necessidade da disjunção não se segue a necessidade de nenhuma das proposiçóes, ou seja, a seguinte implicação é inválida: $(\mathrm{p} \vee \neg \mathrm{p})$ $\rightarrow(\mathrm{p} \vee \neg \mathrm{p})$. A implicação que se impóe é a da possibilidade de cada um dos contrários: $(\mathrm{p} \vee \neg \mathrm{p}) \rightarrow(\diamond \mathrm{p} \wedge \diamond \neg \mathrm{p})$. E perguntemos, ainda: tal dupla possibilidade será indeterminada ou determinada, indiferente ou diferencial, simétrica ou assimétrica? Não haverá um terceiro futuro possível? Isto é, não será possível negar a disjunção dos dois contrários e pensar, portanto, a possibilidade da sua conjunção $\neg(\mathrm{p} \vee \neg \mathrm{p}) \rightarrow \diamond(\mathrm{p} \wedge \neg \mathrm{p})$ ? Com efeito, a necessidade da disjunçáo náo faz jus à temporalidade humana que comporta uma dinâmica adaptativa, estratégica, e um quociente de imprevisibilidade ligada à decisão e à ação. Essa dinâmica da incerteza e da emergência convidaria a pensar "amanhâ" como possibilidade de múltiplas possibilidades reticulares imbricadas numa combinatória virtualmente infinita. Assim, "amanhâ", dependendo de $n$ condiçóes, muito incertas e possivelmente incomputáveis "hoje", como a meteorologia, a ondulação do mar e as decisóes contextuais e não-lineares de inúmeros atores, é possível que haja "batalha naval e rendição e tratado de paz" ou "batalha naval com assalto terrestre e prolongamento indefinido em batalha de infantaria" ou "suspensão de batalha naval iminente por destruição das armadas devido a tempestade inesperada e negociação de solução pacífica" etc. Enfim, "amanhā" não nos é "hoje" plenamente inteligível: hipotetizamos, mas desconhecemos.

Nesse sentido, os contrários podem compor-se e desenvolverse no tempo, com uma coesão ontológica robusta, em que o conteúdo da diacronia se preenche e se constrói sistemicamente, organicamente, com graus permanentemente variáveis, porém, invencíveis, de incerteza e de desconhecimento. A disjunção simples é incapaz de captar "hoje" a lógica 
incerta e caótica de "amanhã". Pode ser verdade que, amanhã, "haja ou não haja" batalha naval; mas também pode ser verdade que, amanhã, "haja $e$ não haja" (sendo uma batalha-com-armistício) ou que "nem haja nem não-haja" (sendo uma batalha dissimulada). Por isso, para a inteligência humana, a lógica condicional de "amanhâ" reconstrói-se, como arqueologia hipotética "depoisde-amanhâ". A verdade de amanhã também se pode pensar como sendo móvel, deslocando-se e desestabilizando-se, em função do movimento do momento de enunciação (o ponto focal "hoje") e do momento de avaliaçáo e de reconstrução lógica das causas e das razôes ("amanhâ" ou "depois de amanhâ"). Ao invés, a aparente necessidade da verdade de um dos futuros contrários possíveis, implicando necessariamente a falsidade do outro, poderá sugerir que o verdadeiro seria verdadeiro em-si-e-por-si, como que "desde sempre", independentemente das condiçóes, transcendendo a relação aos locutores e avaliadores, aos atores e decisores, aos componentes contextuais e ao espaçotempo. Dessa maneira, o que será verdade amanhá já seria verdade hoje, e o que será falso amanhã já seria falso hoje, supra ou transtemporalmente.

Uma lógica supra- ou transtemporal e supra- ou transnatural, que adota uma posição de "nenhures", a da visão divina abraçando uno intuito a série de eventos que compóe o mundo, raciocina de modo qualitativamente distinto ao da lógica da incerteza, pretendendo compreender a diacronia do tempo na sincronia do eterno. Assim, todas as proposiçóes possíveis seriam verdadeiras ou falsas em-si-e-por-si, na sua inteligibilidade teo-lógica e metalógica incondicionada, que corresponderia à perspetiva do Inteligente Superior desde a eternidade. Ao abordar-se toda e qualquer proposição sob o ângulo dessa Visão e dessa Potência divina, que transcendem a assimetria entre "jâ" e "ainda não", entre atual e potencial, entre existência e possível, todos os tempos se tornam essencialmente síncronos e todos os espaços essencialmente sintópicos. Quando, guiado pela deusa, Teodoro recebe a graça de ver, de fora do tempo, o "verdadeiro mundo atual", o apartamento superior da pirâmide infinita dos mundos possíveis, ele participa da inteligência divina e abarca toda a região cognitiva dos possíveis com seus graus de perfeição, daí o êxtase de ver-em-Deus a "Ciência una e completa" do real.

Nessa lógica do Calculador-Criador Máximo, a hipótese da policronia e da politopia da verdade não desmultiplica nem fragmenta as tabelas de valores de verdade com novas valências paradoxais, mas se dissolve totalmente na ucronia pancrónica e na utopia pantópica de uma operação metalógica autoeficaz: a intuição divina do real, na sua unidade otimamente unificante 
(uno intuito) e na sua verdade superiormente verificante, ligada à vontade de Bem do Criador Absoluto que se verifica na Criação e, consequentemente, faz convergir ens totum para o unum, verum, bonum, pulchrum. Portanto, para uma lógica metafísica, teónoma, que pensa a verdade reconstituindo a Visão presciente de um Calculador-Criador, o "ainda-não-ser" do futuro coincide com o "já-ser" dos existentes passados e presentes, ambos fruindo da mesma Realidade desde antes do tempo, desde a computação pré-Criadora, desde quando todos os possíveis eram somente pensamentos de Deus, em Deus. Nesse contexto, impóe-se a necessidade de haver valores de verdade determinados para o passado e para o futuro, porque a verdade é determinada: a omnipotência divina cria livremente, mas em razão da sua inteligência do verdadeiro ou do inteligível enquanto tal. A inteligência e a vontade divinas demonstram a sua unidade sinérgica na Criação. Deus conhece e quer o Melhor: a verdade do que foi, do que é e do que será. A modalidade que decorre da "decisão de verdade" é a contingência de uma decisão livre, omnisciente e omnipotente: uma contingência ordenadora de todos os tempos e de todas as conexôes temporais que assegura a estabilidade atemporal dos valores de verdade de cada um dos múltiplos e contrários futuros contingentes.

Apesar de Deus se autodeterminar a criar pela sua melhor ideia de mundo, a contingência do que foi, do que é e do que será não se deixa absorver pela necessidade. Descobre-se somente que a Contingência criadora não é uma arbitrariedade cega, contudo, uma Ordem totalizante, estruturada pela Inteligência que calcula o Melhor e pela Vontade que prefere o Melhor. A crença humana na abertura do futuro é salva condicionalmente pela adesão fiducial, metafísica, à ficção de uma Pessoa Absoluta, ficção essa que permite transformar a lógica do "evento incerto e indeterminado" numa hermenêutica da "ação criadora autodeterminada" produtora de eventos harmónicos, expressão de uma Suprema intencionalidade subjetiva com seu projeto de construção plenamente significante e inteligente.

Porém, independentemente de a lógica dos futuros contingentes ser configurada pela mediação imaginária de uma inteligência infinita da Série Total ou de uma inteligência finita do simples instante fragmentário ou da conexão local entre instantes, onde o Todo também se exprimiria, isto é, independentemente da ancoragem atemporal ou temporal da lógica, mantém-se incontornável um constrangimento de ordem modal que requer o evitamento da necessidade para salvaguardar a abertura do futuro. Por conseguinte, sendo $p$ e não- $p$ proposiçóes contrárias, a disjunção poderá ser 
considerada necessária, mas nenhuma das unidades proposicionais poderá ser necessariamente verdadeira ou necessariamente falsa. Quer dizer, se as afirmaçóes sobre acontecimentos contingentes futuros forem agora verdadeiras ou falsas, o futuro só permanece em aberto se tais acontecimentos forem possivelmente verdadeiros epossivelmente falsos. Simetricamente, deve manter-se a contingência dos eventos passados, pois, se o passado cede à pressão da necessidade, haverá um contágio modal do passado sobre o futuro enquanto "passado virtual". A essa condição mínima pode acrescentar-se a polivalência lógica dos valores de verdade e, portanto, a sua instabilidade e condicionalidade, em função do espaço-tempo, do contexto actancial ou situaçáo vital, da estrutura gramatical, do(s) locutor(es), do(s) ator(es) e do(s) intérprete(s) ou avaliador(es). Nesse sentido, os futuros contingentes poderão ser "nem verdadeiros nem falsos", ou "verdadeiros-e-falsos" ou "todos (hipoteticamente) verdadeiros" ou "todos (temporariamente) falsos".

Do ponto de vista meramente lógico, quer haja um Deus a favor do Melhor ou um Génio maligno tendendo para o Pior ou um simples operador finito buscador de sentido e evitador de contradição, a abertura ou clausura do futuro revela-se um objeto de fé indecidível. Em última instância, há opções fundamentais, metalógicas, que inclinam (sem necessitar) para a crença na abertura ou na clausura do futuro. Qualquer formulação ou formalização lógica é ambiguamente permeável aos influxos metafísicos e existenciais que tacitamente procedem das línguas naturais, das formas de vida e das práticas sociossimbólicas onde se inventa o jogo de opostos e de compostos entre "agir" e "acontecer", razão e causa, pessoa e coisa, eu e Isso. Escolher a abertura ou a clausura do futuro pode certamente conjugar-se com a pré-determinação ou pré-indeterminaçáa dos valores de verdade dos futuros possíveis. Todavia, tal escolha transporta uma galeria de cosmovisóes éticas incomensuráveis. Escolher abertura ou clausura significa tornar-se responsável por um modo de responsabilidade; portanto, significa escolher-se como habitante de um mundo de vida possível.

\section{DeterminaÇÃo e neCessitaÇÁo}

A posição de Aristóteles relativamente aos futuros contingentes anuncia uma indeterminação lógica mínima que se harmoniza parcialmente com a abertura do futuro, deixando insolúvel o dilema que nos deve ocupar neste ensaio: a relação entre dois princípios aparentemente antagónicos, o 
princípio de verdade ou determinação dos futuros contingentes e o princípio da abertura indeterminada do futuro. Com efeito, em De interpretatione ( 9 , 19a 23-38), Aristóteles (1995, p. 30) recusa a universalidade da necessidade da verdade, fazendo a apologia da possibilidade e da aleatoriedade na atualização de possibilidades concorrentes. A verdade dos possíveis - de que os futuros contingentes são exemplos emblemáticos - permanece indeterminada até à atualização de um dos possíveis. Contudo, ainda que a indeterminação seja resolvida somente a posteriori, Aristóteles conserva a sua confiança na lógica bivalente como espaço da inteligibilidade. A possibilidade conceptual de futuros não-necessários e não-absurdos exige obediência ao princípio de não-contradição (porque é impossível ou "impensável” que um futuro seja verdadeiro e falso, afirmado e negado, simultaneamente) e ao princípio de terceiro excluído (é impossível ou "impensável” haver um "terceiro futuro desconhecido", uma síntese de verdade e de falsidade, de afirmação e de negação, ou um composto de dois futuros contrários). Citemos a célebre passagem de Aristóteles:

O que é, necessariamente é, quando é; e o que não é, necessariamente não é, quando não é. Porém, nem tudo o que é, necessariamente é; e nem tudo o que não é, necessariamente não é. Pois, dizer que tudo o que é, é por necessidade, quando é, não é o mesmo que dizer incondicionalmente que é por necessidade. Do mesmo modo, quanto ao que não é. E o mesmo se aplica aos contraditórios: tudo necessariamente é ou não é, e será ou não será; mas não se pode dividir e dizer que um ou outro contraditório é necessariamente. Quer dizer, por exemplo: é necessário que haja ou não haja uma batalha naval amanhă; mas não é necessário que uma batalha naval aconteça amanhã nem que não aconteça - embora seja necessário que aconteça ou não aconteça. Portanto, dado que as proposiçóes são verdadeiras de acordo com o modo como a realidade é, é óbvio que na medida em que a realidade permitir contrários segundo o acaso, o mesmo se aplicará necessariamente a proposiçōes contraditórias. Tal acontece com as coisas que não são sempre assim ou que não sấo sempre não assim. Com tais coisas, é necessário que um ou outro dos contraditórios seja verdadeiro ou falso - não, porém, este ou aquele, mas segundo o acaso; ou que um seja verdadeiro, ao invés do outro, contudo ainda náo verdadeiro ou falso. (9, 19²3-38; ARISTÓTELES, 1995, p. 30).

A "lógica do que é" reconduz o real ao necessário, mas a "lógica do que pode ser ou náo ser" situa-se na contingência que tem a marca da ignorância própria da temporalidade imperscrutável que define as coisas futuras. Portanto, no regime do "ainda não", a lógica da necessidade fica suspensa e, na 
expetativa da realização inconclusa, a forma da não-contradição oferece apenas uma morfologia lógica mínima, material e semanticamente indeterminada. As afirmaçôes relativas aos futuros contingentes ilustrariam uma dissociação excecional e assimétrica entre matéria ativa e forma conceptual, entre semântica e sintaxe, em favor do primado da matéria sobre a forma e da semântica sobre a sintaxe, na constituição da verdade (que não é necessariamente verdadeira). Carente de matéria plenamente atualizada e de semântica pragmaticamente instanciada, o possível é somente o náo-contraditório indefinido ou ambíguo que, em si e por si, não é ainda "nem verdadeiro nem falso", embora tenha de vir a ser "ou verdadeiro ou falso".

Todavia, a grande dificuldade nessa exceção lógica reside no absurdo do "devir verdadeiro ou falso". Pode uma proposição tornar-se verdadeira e/ou falsa? Pode o verdadeiro ser descritível como processo aleatório, espontâneo, emergente ou livre de realização autoverificante que sintetiza contrários? Como conceber o processo e a passagem da indeterminaçấo lógica ("hoje", ante facto) para a determinação lógica ("amanhâ", post facto)? Como poderá uma proposição ser verdadeira "amanhâ" sem ser - real e logicamente - verdadeira "ontem", "hoje" e "sempre" (apesar da eventual ignorância do enunciador da proposição)? Será absolutamente impossível reduzir as verdades contingentes a verdades necessárias? Para que essas questóes, e suas reivindicações tácitas, sejam inteligíveis, será necessário postular a contingência da verdade, o que implica a subordinação da lógica à onto-lógica. No entanto, sendo assim, em regime de heteronomia, a lógica e a construção lógica do mundo implodem como formas representacionais vazias e arbitrárias, axiomas indemonstráveis, objetos de fé racional, esquematizaçóes confabulatórias do real. Não surpreende, então, que os futuros contingentes tenham sido integrados em grandes narrativas meta-lógicas que ressalvam a unidade totalizadora e estabilizadora do sentido (i.e., a determinação lógica da realidade), obviando o ininteligível devir anacrónico do "indeterminado" ("nem verdadeiro nem falso") em "determinado" ("ou verdadeiro ou falso").

Entre as grandes narrativas metalógicas que evitam a temporalização desagregadora da verdade, identificamos duas grandes famílias: uma com eixo Estoico-Espinosista, onde ser e logos se fundem na completude de uma determinação monista, e outra com um eixo Augustiniano-OckhamistaLeibniziano, onde ser e logos se harmonizam com espontaneidade interna múltipla e cuja coesão íntima repousa numa Inteligência que vê o Todo desde antes do tempo. Tomando a fábula metalógica de Leibniz como paradigmática da harmonizaçáo da verdade pré-determinada do futuro com 
a espontaneidade das substâncias individuais (incluindo a liberdade dos atores humanos), iremos proceder à análise da sua arquitetura dinâmica para compreendermos como a determinaçáo da verdade/falsidade do futuro ante facto não é defensável como princípio lógico atómico isolado, exigindo uma complexa macro-hipótese epistémica e ontoteo-lógica: o "sistema novo" da Harmonia e da Entr'expressão, que Leibniz "[...] ousa declarar demonstrada” (LEIBNIZ, Monadologie, \$. 59; GP VI, p. 616).

Em Leibniz (De rerum originatione radicali; GP VII, p. 305) o "possível" é objeto de uma definiçấo positiva, ultrapassando a noção de nãocontradição ou de não-absurdo lógico e revelando a "força" imanente que age continuamente em tudo o que é substancial. O possível encerra "[...] uma tendência para existir" (tendentia ad existendum) ou "[...] um esforço para a existência” (conatus ad Existentiam) (LEIBNIZ, GP VII, p. 289), cuja intensidade é proporcional à quantidade de essência. Do exterior vem somente obstáculo e limitação, as condiçôes constrangedoras de coexistência harmónica dos possíveis. Num breve texto sem título que apresenta uma cadeia de 24 teses metafísicas fundamentais, Leibniz (GP VII, p. 289-291) afirma a dinâmica futurível (Existiturus) das infinitas essências concebíveis, cuja competição para existir é regulada pelas condiçóes extra-lógicas de compossibilidade ótima, contendo o máximo de variedade e realidade, e pelo ato criador de um ser necessário que, necessariamente, pensa e deseja a melhor série de possíveis, isto é, o melhor mundo possível. Retenhamos o núcleo seguinte do texto:

(5) Sed quae causa facit ut aliquid existat, seu ut possibilitas exigat existentiam, facit etiam ut omne possibile habeat conatum ad Existentiam, cum ratio restrictionis ad certa possibilia in universali reperiri non possit. $[\ldots]$

(7) Verum hinc non sequitur omnia possibilia existere: sequeretur sane si omnia possibilia essent compossibilia. [...]

(9) Interim ex conflictu omnium possibilium existentiam exigentium hoc saltem sequitur, ut Existat ea rerum series, per quam plurimum existit, seu series omnium possibilium maxima. (LEIBNIZ, GP VII, p. 289-290)

Há um acréscimo de sentido no "possível" que o torna irredutível a meras noçôes vagas de lógica modal: não-impossível ou não-contraditório e não-necessário ou contingente. $\mathrm{O}$ possível remete para a causalidade imanente à força substancial. Tal afigura-se evidente sobretudo, pois os possíveis não paralisam em nenhuma "indiferença de equilíbrio" (LEIBNIZ, Essais de 
Théodicée, \$. 46; GP VI, p. 128). Ao invés, eles preferem a existência, competem entre si pela existência e pendem ou desequilibram-se para algo de determinado. Entre as inúmeras passagens em que Leibniz descreve o encadeamento ontoteológico dos “infinitos possíveis", selecionamos os $\$ \$$. 53-56 da Monadologia pela sua densidade argumentativa:

53. Or, comme il y a une infinité des Univers possibles dans les Idées de Dieu et qu'il n'en peut exister qu'un seul, il faut qu'il y ait une raison suffisante du choix de Dieu, qui le détermine à l'un plutôt qu'à l'autre.

54. Et cette raison ne peut se trouver que dans la convenance, ou dans les degrés de perfection, que ces Mondes contiennent, chaque possible ayant droit de prétendre à l'Existence à mesure de la perfection, qu'il enveloppe.

55. Et c'est ce qui est la cause de l'Existence du Meilleur, que la sagesse fait connaitre à Dieu, que sa bonté le fait choisir, et que sa puissance le fait produire.

56. Or cette Liaison ou cet accommodement de toutes les choses créées à chacune et de chacune à toutes les autres, fait que chaque substance simple a des rapports qui expriment toutes les autres, et qu'elle est par conséquent un miroir vivant perpétuel de l'univers. (LEIBNIZ, Monadologie, $\$ \$$. 5356; GP VI, p. 615-616).

O encadeamento das proposiçóes que compóem a Hipótese da Harmonia deve ser reconstruído de modo a enfatizar o vínculo que liga a determinação e a espontaneidade dos futuros contingentes enquanto contingentes atemporalmente "seguros" (vínculo cujo aspeto paradoxal a Hipótese pretende desfazer):

a Infinitude dos possíveis organiza-se em Mundos ou Universos, sendo que "[...] mundo é a série toda e a coleção toda de tudo o que existe" ${ }^{3}$, mas esta "cadeia" (catena, series) total de estados, eventos ou coisas em movimento pertence ao regime ontológico do "[...] agregado das coisas finitas" (Aggregatum rerum finitarum) (LEIBNIZ, De rerum originatione radicali; GP VII, p. 302303) e carece, portanto, daquela completude que cabe somente às substâncias individuais e singulares;

1. a passagem à existência de um Mundo possível efetua-se por escolha (contingente, livre) de Deus;

\footnotetext{
${ }^{3}$ Retenhamos a seguinte definição leibniziana de mundo: "J'appelle monde toute la suite et toute la collection de toutes les choses existantes, afin qu'on ne dise point que plusieurs mondes pouvaient exister en différents temps et différents lieux." (LEIBNIZ, Essais de Théodicée, \$. 8; GP VI, p. 107).
} 
2. a escolha de Deus é autodeterminada pela razão suficiente; procede da perceção divina dos graus de perfeição dos infinitos mundos e da discriminação do "[...] melhor plano possível onde há a maior variedade com a maior ordem”, na expressão dos Princípios da natureza e da graça $a^{4}$, que se simboliza na sugestiva "pirâmide dos mundos" descendo até ao infinito, segundo a alegoria final dos Ensaios de Teodiceia, \$. 4165);

3. a razão suficiente é, em Deus, o princípio do Melhor que se concretiza no sistema de possíveis que contém o máximo de realidade, de unidade e de variedade (se não houvesse um mundo melhor, optimum, entre os possíveis, e se Deus não soubesse identificá-lo, Ele não teria criado nenhum);

4. a máxima conveniência ou ligação de todas as substâncias no Melhor mundo possível implica um sistema de relaçóes entr'expressivas e hologramáticas (portanto, a perfeição do Todo exibe-se em cada parte/acontecimento).

No conceito divino do Melhor dos Mundos Possíveis, o único que responde a uma razão para ser criado, está contida a melhor série de Realidade: a comunidade monadológica ótima que se exprime em açôes de substâncias espontâneas que encerram em si a potência necessária e suficiente para cumprirem a sua existência. Assim, cada singularidade realiza e exprime espontaneamente a Ordem Ótima Total, ao seu modo determinado. Tal significa que a contingência dos eventos não é absolutamente contingente, todavia, determinada pelo Melhor e pela verdade ou realidade do Melhor. Deus cria o melhor sistema contingente, intuindo sapientemente todos os eventos na sua cadeia inteira, ab ovo, desde antes de criar, como se intuísse as propriedades geométricas necessárias do círculo na simples ideia de círculo.

\footnotetext{
${ }^{4}$ Convém citar a dita passagem sobre a razão divina de criar este mundo, ao invés de outro ou ao invés de nada: “(\$. 10) Il suit de la perfection suprême de Dieu, qu’en produisant l'univers il a choisi le meilleur plan possible, où il y ait la plus grande variété, avec le plus grand ordre [...]. Car tous les Possibles prétendant à l'existence dans l'entendement de Dieu, à proportion de leur perfection, le résultat de toutes ces prétensions doit être le monde actuel le plus parfait qui soit possible. Et sans cela il ne serait pas possible de rendre raison, pourquoi les choses sont allées plutôt ainsi quautrement." (LEIBNIZ, Principes de la nature et de la grâce, \$. 10; GP VI, p. 603).

${ }^{5}$ Eis a célebre representação arquitetónica dos mundos infinitos e dos seus graus diferenciais de perfeição: "Les appartements allaient en pyramide; ils devenaient toujours plus beaux à mesure qu'on montait vers la pointe, et ils représentaient de plus beaux mondes. On vint enfin dans le suprême qui terminait la pyramide et qui était le plus beau de tous; car la pyramide avait un commencement, mais on n'en voyait point la fin; elle avait une pointe, mais point de base; elle allait croissant à l'infini. C'est, comme la déesse l'expliqua, parce qu'entre une infinité de mondes possibles, il y a le meilleur de tous, autrement Dieu ne se serait point déterminé à en créer aucun; mais il n'y en a aucun qui n'en ait encore de moins parfaits au-dessous de lui: c'est pourquoi la pyramide descend à l'infini." (LEIBNIZ, Essais de Théodicée, \$. 416; GP VI, p. 364).
} 
Intuir a futurição do mundo evoca o desdobramento da substância, embora o mundo seja um agregado e não uma substância completa e una (Discours de Métaphysique, $\$$. XIII $\left.{ }^{6}\right)$. De facto, em Leibniz, o horizonte ontoteológico está intimamente implicado não só com a conceção lógica de verdade e de sujeito proposicional, mas também com a conceção ontológica ou, melhor, ontodinâmica, de substância, causalidade e ação. No Discurso de Metafísica e na Correspondência com Arnaud, essas conexôes estão já firmemente estabelecidas, mostrando o vigor da conjunçáo entre liberdade e inteligibilidade.

\section{Predicaçáo e Futuriçáo}

O conceito de verdade como inclusão ou inesão dos predicados no sujeito e o conceito de substância individual como princípio de ação entr' exprimemse, designando uma atração pela identidade expressa ou virtual de " $\mathrm{S}=\mathrm{P}$ ", e remetendo ambos para o Ato cognitivo e volitivo infinito que compreende e cria, na noção inteira (mas não-completa, não-una) do Agregado-Mundo, todo o sistema de predicados ou ações inerente a cada sujeito ou substância. $\mathrm{O} \$ .8$ do Discurso de Metafísica esclarece essa conexão identitária crucial:

Or il est constant que toute prédication véritable a quelque fondement dans la nature des choses, et lors qu'une proposition n'est pas identique, c'est-àdire lors que le prédicat n'est pas compris expressément dans le sujet, il faut qu'il y soit compris virtuellement, et c'est ce que les Philosophes appellent in-esse, en disant que le prédicat est dans le sujet. (LEIBNIZ, GP IV, p. 433)

Desse modo, os futuros contingentes estão incluídos na noção de cada substância e expóem o seu autodesenvolvimento, conforme à ideia e à forma total do Melhor. Portanto, o pecado de Adão ou as vitórias de Alexandre Magno são açóes contingentes da responsabilidade daquele Adão e daquele Alexandre Magno, naquele mundo, mas que decorrem da sua "natureza ontológica" específica, tal como esta foi intuída e querida por Deus, quando concebeu e criou o mundo. A sua autonomia de substâncias individuais obedece espontânea e infalivelmente à Teoteleonomia que lhes atribuiu $a$

\footnotetext{
${ }^{6}$ Uma substância encerra em si a completude dos seus atributos temporais, a sua unidade pancrónica com as múltiplas biografias possíveis que o futuro atualizará segundo o princípio do ótimo e da compossibilidade: "Nous avons dit que la notion d'une substance individuelle enferme une fois pour toutes tout ce qui lui peut jamais arriver, et qu'en considérant cette notion, on y peut voir tout ce qui se pourra véritablement énoncer d'elle, comme nous pouvons voir dans la nature du cercle toutes les propriétés qu’on en peut déduire" (LEIBNIZ, Discours de métaphysique, \$. 13; GP IV, p. 436).
} 
priori uma predicação futura verdadeira, definindo um processo biográfico de individuação como "Adão" e "Alexandre Magno", atores livres de açóes pré-determinadas e expressões singulares da ligação simpatética e simpoiética de todo o universo ${ }^{7}$. Deus conhece cada haeccitas no Todo a priori (sem que tal implique necessidade metafísica), e o homem só conhece parcialmente a história de algumas singularidades do Todo sempre a posteriori (sem que tal implique acaso cego ou fatum desordenado):

Dieu voyant la notion individuelle ou hecceitté d'Alexandre, y voit en même temps le fondement et la raison de tous les prédicats qui se peuvent dire de lui véritablement, comme par exemple qu'il vaincrait Darius et Porus, jusqu’à y connaître a priori (et non par expérience) s'il est mort d'une mort naturelle ou par poison, ce que nous ne pouvons savoir que par l'histoire. Aussi quand on considère bien la connexion des choses, on peut dire qu'il y a de tout temps dans l'âme d'Alexandre des restes de tout ce qui lui est arrivé, et les marques de tout ce qui lui arrivera, et même des traces de tout ce qui se passe dans l'univers, quoiqu'il n'appartienne qu'à Dieu de les reconnaitre toutes. (LEIBNIZ, DM, §. 8; GP IV, p. 433)

$\mathrm{Na}$ "noção completa" de um sujeito, Deus vê todos os predicados (qualquer que seja a relação modal ou temporal entre $S$ e P). Ciência e Realidade coincidem numa cognição infinita, mas essa coincidência sofre uma anamorfose num intelecto finito e, aí, permanece obscura ou confusa. Ver o infinito diacronicamente, no seu desdobramento, ou vê-lo imediata e sincronicamente, ocupando o seu centro sem circunferência, constituem as duas visóes que distinguem e aproximam Deus e homem, como Leibniz defende, nos Princípios da natureza e da graça, \$. 13:

[...] le présent est gros d'avenir, le futur se pourrait lire dans le passé, l'éloigné est exprimé dans le prochain. On pourrait connaitre la beauté de l'univers dans chaque âme, si l'on pouvait déplier tous ses replis, qui ne se développent sensiblement qu'avec le temps. [...] Chaque âme connait l'infini, connaît tout, mais confusément [...]. Dieu seul a une connaissance distincte de tout, car il en est la source. On a fort bien dit, qu'il est comme centre partout; mais sa circonférence n’est nulle part, tout lui étant présent immédiatement, sans aucun éloignement de ce centre. (LEIBNIZ, GP VI, p. 604).

\footnotetext{
${ }^{7}$ Sobre a relação entre o princípio de individuação e o princípio da predicaçăo verdadeira, vide RAUZY, 2001.
} 
Ademais, intensificando a obscuridade, os predicados contingentes futuros procedem de decretos e atos livres. Por conseguinte, os futuros contingentes são intrinsecamente verdadeiros, porém, não-necessariamente nem autoevidentemente verdadeiros. Nada acontece sem razáo, mas algo acontece sem razão analisável, isto é, sem razão necessitante. Na fórmula lapidar de Leibniz, visando a amenizar as objeçôes de $\mathrm{Arnaud}^{8}$, sustém-se que "[a]s verdades contingentes inclinam sem necessitar":

En effet en consultant la notion que j'ay de toute proposition véritable, je trouve que tout prédicat nécessaire ou contingent, passé, présent ou futur, est compris dans la notion du sujet, et je n'en demande pas davantage.

Je crois même que cela nous ouvrira une voie de conciliation, car je m'imagine que $M$. Arnaud n'a eu de la répugnance à accorder cette proposition, que parce qu'il a pris la liaison que je soutiens pour intrinsèque et nécessaire, et moi je la tiens intrinsèque, mais nullement nécessaire; car je me suis assez expliqué maintenant qu'elle est fondée sur des décrets et actes libres. Je n'entends point d'autre connexion du sujet avec le prédicat que celle qu'il y a dans les vérités les plus contingentes, c'est-à-dire qu’il y a toujours quelque chose à concevoir dans le sujet, qui sert à rendre raison, pourquoi ce prédicat ou événement lui appartient, ou pourquoi cela est arrivé plutôt que non. Mais ces raisons des vérités contingentes inclinent sans nécessiter. (LEIBNIZ, GP II, p. 46).

A inteligibilidade das verdades contingentes ou de facto deve procurarse em dois decretos livres gerais: (1) que Deus faz sempre o melhor (livre e contingentemente, pois o contrário, o "imperfeito" ou o "menos bom", não implicam impossibilidade) e (2) que o homem fará sempre o que lhe parecerá ser o melhor (também livremente, porque a determinação não implica a eliminação da vontade) (LEIBNIZ, DM, \$. XIII). Contrariamente às verdades geométricas eternas que são absolutamente necessárias em todos os mundos possíveis, as verdades contingentes só são verdadeiras no melhor dos mundos, se Deus o criar.

Daí decorre que a análise das verdades necessárias se resolve em proposições autoidênticas, inteiramente evidentes, ao passo que a análise das contingentes permanece sempre na obscuridade, exigindo o impossível, isto é, o conhecimento do contínuo inteiro do Real com as infinitas conexóes entre os infinitos possíveis. Porém, dessa forma, como evitar que o contingente

\footnotetext{
${ }^{8}$ No que respeita à controvérsia com A. Arnaud, veja-se GAUDEMAR (1994, p. 215-228).
} 
e o necessário não se toquem e se fundam no infinito (segundo a lei da continuidade)? Na verdade, salvar a contingência do futuro, evocando apenas que o contrário é não-contraditório, ignora o facto essencial do dever-ser, da atualização deôntica do melhor ser. Aqui, resiste um sentido ontológico do necessário que se expóe no défice de potência para ser de outro modo. Afigurase-nos sustentável, então, que a verdade infalível do futuro escolhido por Deus como Melhor permaneça logicamente e epistemicamente contingente, mas ontologicamente e dinamicamente necessária. Caso contrário, aconteceria que "este mundo poderia, a qualquer instante, não dever-ser, não devercumprir, este mundo", entretanto, "este mundo só pode ser o que deve ser: este mundo", porque "S é P". Portanto, de acordo com Leibniz, o Universo não pode refulgurar in medias res; não tem força ínsita para devir "outro", mas somente para desenrolar-se, cumprir-se, segundo o quantum determinado da sua força infusa, desde sempre, para sempre. Por isso, a história do Universo é o autodesdobramento do seu conteúdo energético primordial.

Com a Sua visão do infinito, Deus vê - uno intuito - o passado, o presente e o futuro, sincronizados num cálculo infinitesimal exaustivo ${ }^{9}$. A necessidade que se insinua do interior da Potência dessa Visão, fundamento do facto de os futuros contingentes serem "verdadeiros" e "certos" (certains, assurés) em relação a este Universo, não é rigorosamente lógica. Trata-se antes de uma "necessidade acidental", "histórica", "condicional" ou "hipotética" (ex hypothesi), que implica, do ângulo de Deus, uma probabilidade igual a 1 para todos os eventos contingentes, isto é, uma contingência paradoxalmente sem incerteza e sem cálculos probabilísticos. Contudo, também do ângulo da experiência em geral, apesar da ignorância dos atores (ignorância que protege a sua crença de autoeficácia), não é possível fazer nada nem é possível acontecer nada que não esteja já pré-determinado como Melhor: tudo está "escrito" nas disposiçôes intrínsecas para a ação em cada substância, na sua Noção Completa que exprime um Decreto Livre Primordial. Para Deus, é tâo autoevidente a análise finita de uma figura geométrica (ou de um número) como a análise infinita da biografia completa de cada ser vivo, passado, presente ou futuro, sobre a terra. Todavia, as conexôes entre $\mathrm{S}$ e $\mathrm{P}$ são qualitativamente distintas nos dois $\operatorname{casos}^{10}$. No primeiro, Deus vê as notas

\footnotetext{
9 Sobre a relação entre a metafísica do cálculo infinitesimal e a ontologia da continuidade, vide ORIO (2011, p. 93-99).

${ }^{10}$ Entre as diversas passagens sobre esse tópico, veja-se o $\$$. XIII do Discurso de Metafísica: "[...] les futurs contingents sont assurés, puisque Dieu les prévoit, mais on n'avoue pas pour cela, qu'ils soient nécessaires. [...] (J)e dis que la connexion ou consécution est de deux sortes, l'une est absolument
} 
internas, necessárias, de uma ideia no Seu Entendimento; no segundo, porém, Deus vê as ínfimas diferenças de perfeição entre infinitos possíveis que, no Seu Entendimento, determinam a Sua Vontade criadora, mas determinam sem necessitar, pois Deus pode criar ou não criar: esse conhecimento não exclui a liberdade e a espontaneidade da futurição. Como argumenta Leibniz, em Essais de Théodicée, $1^{\text {a }}$ parte, (\$. 36; GP VI, p. 123), “[...] la prescience en elle-même n'ajoute rien à la détermination des futurs contingents, sinon que cette détermination est connue, ce qui n'augmente point la détermination ou la futurition de ces événements". Por conseguinte, para Deus que abarca todo o real numa intuição singular, ver os futuros contingentes significa ver a totalidade da história (natural e civil) com todas as crónicas possíveis, coordenando as infinitas perspetivas e intuindo, numa unidade sincrónica e pancrónica, o "[...] jogo policrónico de uma multiplicidade de histórias que se entre-exprimem mutuamente" (CARDOSO, 2005, p. 96).

$\mathrm{Na}$ interseção entre o entendimento e a vontade, a verdade dos futuros contingentes manifesta, segundo Leibniz (Essais de Théodicée, $1^{\text {a }}$ parte, \$. 3941), não só uma "ciência média" (ao modo de L. de Molina), mas também uma pré-determinação (ao modo de St. Agostinho). A novidade da conciliação leibniziana consiste na ideia de uma "pré-determinação não-necessitante", a qual invalida a aplicação do princípio de contradição aos futuros contingentes (pois este seria necessitante). Dois possíveis contrários permanecem igualmente possíveis e essa estrita equipossibilidade só é vencida por uma razáo inclinante ou desequilibrante: "[...] uma razão prevalente que leva a vontade (divina ou humana) a escolher" (LEIBNIZ, Essais de Théodicée, \$. 45; GP VI, p. 127), correspondendo à representação do bem, a única capaz de vencer representaçôes contrárias. Assim, enquanto Ciência de Visão da "região dos possíveis", a presciência divina - tal como a pura lógica formal - é indiferente face à liberdade; ao invés da Vontade ordenadora que prefere o Bem e que decide inclinar todas as vontades à adesáo livre ao Bem. Dessa conjunção resulta a síntese entre verdade determinada dos futuros contingentes e indestrutibilidade da contingência.

nécessaire, dont le contraire implique contradiction, et cette déduction a lieu dans les vérités éternelles, comme sont celles de géométrie; l'autre n'est nécessaire qu'ex hypothesi, et pour ainsi dire par accident, mais elle est contingente en elle-même, lorsque le contraire n'implique point. Et cette connexion est fondée, non pas sur les idées toutes pures et sur le simple entendement de Dieu, mais encore sur ses décrets libres, et sur la suite de l'univers." (LEIBNIZ, GP IV, p. 437). 


\section{ACONTECER E FAZER ACONTECER}

A razão determinante do Bem torna-se a força intrínseca, a disposição constitutiva e a lei natural de todas as liberdades que fazem por si mesmas acontecer os futuros contingentes. Emerge uma nova identidade entre Lógica e Ontologia, Ontologia e Ética: ratio sive causa, causa sive lex insita, lex sive vis primitiva, vis sive bonum! Em última instância, a segurança da verdade e a certeza objetivo-subjetiva (em Deus) dos futuros contingentes requerem uma articulação entre a Lógica e a Dinâmica, isto é, entre a esfera das razôes determinantes e a das forças autónomas. Porém, essa articulação contém um ponto cego, um núcleo de opacidade, porque só um Entendimento infinito conhece plenamente as razões determinantes que são as Suas, ou seja, só Deus se conhece a Si próprio, só Ele pensa inteiramente os Seus pensamentos e só Ele pode ter acesso às verdades contingentes.

Para um calculador finito, a existência dessas razôes evita o sem-sentido de uma ordenação aleatória dos acontecimentos e das açôes. Essa intolerância leibniziana a uma ontologia fragmentária ou a uma ontologia do caos e das emergências probabilísticas oculta uma negligência da irregularidade imprevisível dos eventos e da gratuidade injustificável do mal (ou do "nonoptimum"). No entanto, mais do que negligência, verifica-se uma neutralização do ininteligível pela concentração do Real na Auto-Inteligência de Deus, a que se pode aceder pela covisão virtual que constitui o ato de fé na operação ótima de Razão-em-Tudo que funda a contingência do universo no ser necessário. Se algo é condicionalmente possível, então algo é incondicionalmente necessário e, nessa Necessidade única e última, repousa a "necessidade da possibilidade e da contingência" de todos os acontecimentos singulares e de todos os predicados temporais.

Quais as implicaçóes éticas da pré-determinação da contingência? Se nenhum sujeito pode fazer nada que não esteja contido na sua "verdade pré-determinada", não haverá uma redução do Eu a uma dramatis persona que cumpre infalivelmente a sua essência? Se nenhuma substância pode surpreender Deus com uma novidade ativa, produzindo um evento que Ele não tenha pensado e já preferido entre todos os possíveis, desde sempre, desde o Eterno, não será vã a intensidade emocional da culpa, do arrependimento, da expetativa, do mérito, da honra e de todas as emoçôes morais? Leibniz defender-se-ia, apelando para uma pré-determinação cognitiva dos possíveis que não implica pré-destinação volitiva. Nessa ótica, uma autopoiesis existencial ou moral inovadora - uma mudança de essência pelo trabalho da existência 
autotransformadora - seria uma falsidade absurda ou uma contradiçáo (teoonto)lógica: esse sujeito atual conteria predicados pertencentes a outros sujeitos possíveis inatuais ou predicados que virtualmente lhe pertenceriam noutro mundo possível inatual que Deus não criou! A "verdade" de um Eu desenvolve-se na realização biográfica espontânea de todos os predicados/açóes contidos na sua "noção", cumprindo a ordem do Todo. Deus viu o Melhor e criou o seu Agregado, no entanto, é cada Eu (e não Deus-em-mim) que faz acontecer livremente os seus eventos. O conceito de "Eu real verdadeiro" obedece a uma identidade pré-determinada que o Eu desconhece, mas que, na sua autoignorância crassa, não pode não realizá-la livremente.

Uma autoscopia ou autognosia completas do Eu presente é imaginável e implicaria a visão simultânea de todos os futuros contingentes do Eu e dos seus graus de perfeição, ou seja, o Eu compreenderia todas as suas razóes determinantes. A dinâmica determinada do Eu mimetiza a dinâmica do Todo, de tal modo que a descrição determinista da economia desenvolvimental do Eu é idêntica àquela que Pierre-Simon de Laplace proporá para o Universo sem a Hipótese-Deus. Recorde-se o $\$$. XIV do Discurso de Metafísica:

En effet rien ne nous peut arriver que des pensées et des perceptions, et toutes nos pensées et perceptions futures ne sont que des suites quoique contingentes de nos pensées et perceptions précédentes, tellement que si j'étais capable de considérer distinctement tout ce qui m'arrive ou paraît à cette heure, j'y pourrais voir tout ce qui m'arrivera, ou qui me paraîtra à tout jamais; ce qui ne manquerait pas, et m'arriverait tout de même, quand tout ce qui est hors de moi serait détruit, pourvu qu'il ne restât que Dieu et moi. (LEIBNIZ, GP IV, p. 440)

Nesse sistema de tendência panlógica linear (apesar de multilinear, porque multissubstancial), a realizaçáo disposicional do Eu é infalivelmente certa, mas não-necessária; absolutamente verdadeira, mas não-compreensível; teoteleonómica, mas autonomamente operativa; pancronicamente prédeterminada, mas diacrónica e instantaneamente espontânea. Contudo, entấo, interroguemos novamente: qual a relação entre Deus, Eu e o(s) meu(s) Futuro(s)? Eis como, na sua densa troca epistolar com Arnaud, Leibniz responde a essa questão, concentrando-se numa noção de "verdade" cuja razão determinante é a "potência livre":

Je demeure d'accord que la connexion des événements, quoiqu'elle soit certaine, n’est pas nécessaire, et qu'il m’est libre de faire ou de ne pas faire 
ce voyage, car quoiqu'il soit enfermé dans ma notion que je le ferai, il y est enfermé aussi que je le ferai librement. [...] Cependant puisqu'il est certain que je le ferai, il faut bien qu'il y ait quelque connexion entre moi, qui suis le sujet, et l'exécution du voyage, qui est le prédicat, semper enim notio praedicati inest subjecto in propositione vera. Il y aurait donc une fausseté, si je ne le faisait pas, qui détruirait ma notion individuelle ou complète, ou ce que Dieu conçoit ou concevait de moi avant même que de résoudre de me créer; car cette notion enveloppe sub ratione possibilitatis les existences ou vérités de fait ou décrets de Dieu, dont les faits dépendent. (LEIBNIZ, GP II, p. 52)

Entre Deus, Eu, o Futuro e o Todo, há um milagre harmónico que conjuga a espontaneidade dos eventos singulares com a Ordem sistémicoholística, porque toda a "razão" que anima todos os eventos contingentes é essencialmente arquitetónica. Portanto, o modus operandi do "concurso divino" nas ações contingentes reside numa conservação e produção contínuas de ser, sem influxo heterónomo, o que permite a constituição de um sujeito moral que deve responder por tudo o que lhe acontece (como é reiterado no §. XXX do Discurso de Metafísica ${ }^{11}$ ). A condição de possibilidade de um sujeito moral é a espontaneidade e a crença de autoeficácia que se nutre da ignorância total relativamente à pré-determinação sobre a qual assenta a certeza infalível do bem e do mal que, contingentemente, "eu" cometerei. $\mathrm{O}$ "eu" só se conhece plenamente post facto, e a autoignorância é a condição natural do navegante moral in medias res. A maldade ou bondade da sua "essência" manifestam-se nos futuros contingentes que emanam do Eu e que são "certos" para Aquele capaz de ver a Economia do infinito, mas “incertos” para o Eu imerso no processo aberto da ordenação do Melhor. Por conseguinte, o escândalo do "mal" é desativado, pois, na perspetiva do Todo, o "mal" compensa um "bem infinitamente maior", por mais inaparente que seja. Em suma, os futuros contingentes formam uma única verdade, porque se unem no ótimo (lógica, ontológica e eticamente). Sigamos de novo o $\$$. XXX do $D M$ que conduz até à altitude e profundidade abissais da Sabedoria futurante, desdobrando uma economia salvífica que progride para o infinitamente Melhor:

\footnotetext{
${ }^{11}$ A passagem mais expressiva sustém o seguinte: "Dieu en concourant à nos actions ordinairement ne fait que suivre les lois qu'il a établies, c'est à dire il conserve et produit continuellement notre être, en sorte que les pensées nous arrivent spontanément ou librement dans l'ordre que la notion de notre substance individuelle porte, dans laquelle on pouvait les prévoir de toute éternité. De plus en vertu du décret qu'il a fait que la volonté tendrait toujours au bien apparent, en exprimant ou imitant la volonté de Dieu sous des certains respects particuliers, à l'égard desquels ce bien apparent a toujours quelque chose de véritable, il détermine la nôtre aux choix de ce qui paraît le meilleur sans la nécessiter néanmoins" (LEIBNIZ, GP IV, p. 454).
} 
Or cette âme un peu avant que de pécher aurait elle bonne grâce de se plaindre de Dieu, comme s'il la déterminait au péché? Les déterminations de Dieu en ces matières étant des choses qu'on ne saurait prévoir, d'où sait elle qu'elle est déterminée à pécher, si non lors qu'elle pèche déjà effectivement? [...] Mais peut-être qu'il est assuré de toute éternité, que je pécherai? Répondez vous vous-même: peut-être que non; et sans songer à ce que vous ne sauriez connaître, et qui ne vous peut donner aucune lumière, agissez suivant votre devoir que vous connaissez. Mais dira quelque autre, d'où vient que cet homme fera assurément ce péché? La réponse est aisée, c'est qu'autrement ce ne serait pas cet homme. [...] Mais d'expliquer toujours l'admirable économie de ce choix, cela ne se peut pendant que nous sommes voyageurs; c'est assez de le savoir sans le comprendre. Et c'est ici qu'il est temps de reconnaître altitudinem divitiarum, la profondeur et l'abîme de la divine sagesse, sans chercher un détail qui enveloppe des considérations infinies. (LEIBNIZ, GP IV, p. 455).

A Ética fundamental torna-se necessariamente Teo-Lógica. Cada futuro contingente é bom e verdadeiro, ocupando a sua posição própria no sistema da Ordem. Matematicamente, a perceção da verdade contingente parece exigir uma combinação entre analysis situ e cálculo infinitesimal. Cada evento é ótimo no seu tempo como cada predicado é verdadeiro no seu sujeito. Assim, a economia geral do Universo, ordenado pela equilibração majorante dos futuros contingentes mais perfeitos, segundo a "ficção" de Leibniz, constitui, em grande parte, uma exegese empática da melhor página bíblica de lógica sapiencial temporal (Livro do Eclesiastes, 3: 1-8, 11), onde se subjuga o jogo policrónico das singularidades infinitas à sincronia pancrónica, que, em rigor, também se pode denominar sincronia acrónica enquanto dissolução do tempo no Eterno ou, com léxico bíblico, redação da duração inteira no coração de Deus:

Todas as coisas têm o seu tempo, e tudo o que existe debaixo dos céus tem a sua hora. Há tempo para nascer e tempo para morrer; tempo para plantar e tempo para arrancar o que se plantou; tempo para matar e tempo para dar vida; tempo para destruir e tempo para dar vida; tempo para destruir e tempo para edificar; tempo para chorar e tempo para rir; tempo para se afligir e tempo para dançar; tempo para espalhar pedras e tempo para as juntar; tempo para abraçar e tempo para se afastar; tempo para adquirir e tempo para perder; tempo para guardar e tempo para lançar fora; tempo para amar e tempo para odiar; tempo para a guerra e tempo para a paz. [...] Todas as coisas que Deus fez são boas, no seu tempo. Ademais, Deus pôs no seu coração a duração inteira, sem que ninguém possa compreender a obra divina de um extremo ao outro. (Livro do Eclesiastes, 3: 1-8, 11). 
Numa palavra, todos os tempos têm o seu "verbo" ótimo. O bem e o mal são categorias vazias que só funcionam em análises atemporais indeterminadas, pois, no seu tempo determinado, todo o evento é essencialmente bom (e só o ignorante insensato, insapiens, negador de Deus, poderá ver o "mal" onde, desde sempre, por fim, há "bem"). Em última análise, o mal é inexistência: vêlo significa adotar uma "má perspetiva", um ângulo truncado, sobre a realidade. Por isso, na teodiceia cristâ, o mal é persistentemente uma figura do nada: limitação, carência e privação de ser (involuntária no mal físico, mas voluntária no mal moral). Correlativamente, compreender o Universo sob o prisma do mal ou do péssimo seria uma limitação, carência e privação (voluntária) de inteligência. Essa teodiceia, na tradição da paciência e da esperança de Job (aceitando acreditar, sem compreender, o trabalho do bem através do mal), proporciona a melhor consolaçáo sobre a abertura otimamente determinada dos futuros contingentes, porque a Economia do Real é uma economia salvífica: a ontologia e a história são o teatro da soteriologia. Portanto, a atitude ética primordial comporta uma gratidão laudatória incondicional pelo que foi, é e será, por "todo o ser ao invés de nada" e por "cada ser-assim ao invés de outramente". Nesse sentido, a alegoria que fecha a $3^{\text {a }}$ parte dos Ensaios de Teodiceia (\$. 416-417) ilustra exemplarmente qual a atitude sábia do crente após ter vivido a Visão do primado do Bem, do Espontâneo e do Todo (culminando na análise singular da "configuração biográfica" de Sextus ${ }^{12}$ ):

Dans ce moment Théodore s'éveille, il rend grâces à la déesse, il rend justice à Jupiter, et pénétré de ce qu'il a vu et entendu, il continue la fonction de grand sacrificateur avec tout le zèle d'un vrai serviteur de son Dieu, avec toute la joie dont un mortel est capable. (LEIBNIZ, Essais de théodicée, $\$$. 417; GP VI, p. 365).

\footnotetext{
${ }^{12} \mathrm{O}$ Ato Criador tem por objeto um Universo inteiro em que há o máximo de Ser e de Bem atualizáveis (não infinitamente, mas limitadamente, segundo a capacidade da matéria imperfeita e as restrições da compossibilidade, donde resulta a carência e a "imperfeição original conatural a todas as criaturas"). Ora, é no Melhor Universo que nascem Adão, Judas e Sextus, livremente "maus" na sua hora, desde sempre. Portanto, o seu mal inscreve-se num desígnio de bem maior: "Voici Sextus tel qu'il est et tel qu'il sera actuellement. Il sort du temple tout en colère, il méprise le conseil des dieux. Vous le voyez allant à Rome, mettant tout en désordre, violant la femme de son ami. Le voilà chassé avec son père, battu, malheureux. Si Jupiter avait pris ici un Sextus heureux à Corinthe, ou roi en Thrace, ce ne serait plus de ce monde. Et cependant il ne pouvait manquer de choisir ce monde, qui surpasse en perfection tous les autres, qui fait la pointe de la pyramide: autrement Jupiter aurait renoncé à sa sagesse, il m'aurait bannie, moi (Pallas) qui suis sa fille. Vous voyez que mon père n’a point fait Sextus méchant; il l'était de toute éternité, il l'était toujours librement: il n'a fait que lui accorder l'existence, que sa sagesse ne pouvait refuser au monde où il est compris: il l'a fait passer de la région des possibles à celle des êtres actuels. Le crime de Sextus sert à de grandes choses; il en naîtra un grand empire qui donnera de grands exemples." (LEIBNIZ, Essais de Théodicée, \$. 416; GP VI, p. 364).
} 
O júbilo do "crente" funda-se na convicção de que o futuro salva o passado e desenvolve todas as sementes primitivas, onde esteve sempre já contido. As próprias Lamentaçôes de Jeremias desvelam um lastro jubilatório que transformam o desespero em ateísmo prático e pecado contra o próprio Espírito (metalógico) de Deus que se afirma, no princípio e no fim de Tudo, como "Graça amorosa". Nenhum começo é mecânico ou natural, mas Graça onde fulgura o possível eleito entre todos. Nessa "crença otimista", encontra-se ainda a esperança da prevalência arqueoescatológica do Bem que se realiza "sempre já", embora confusamente, nas biografias objetivas de "homens bons" e "homens maus" (pois o crente adere ingenuamente à Justiça retributiva ontológica, movido por uma espécie de libido cognitiva que deseja Equilíbrio, fundação metafísica de uma motivação moral incondicional pelo bem). Assim, Leibniz encontra consolação ética numa crença retributiva que formula nas Remarques sur le livre de l'origine du mal (\$. 27): “[...] la plus grande félicité ici-bas consiste dans l'espérance du bonheur futur, et qu'ainsi on peut dire qu'il n'arrive rien aux méchants qui ne serve à l'amendement ou au châtiment, et qu'il n'arrive rien aux bons qui ne serve à leur plus grand bien.” (LEIBNIZ, GP VI, p. 436).

A metalógica leibniziana que toma a perspetiva da omnipotência e da omnisciência é ostensivamente consoladora da ignorância e do sofrimento e inteiramente justificadora da Bondade divina, propondo um princípio radical: "pan kalòs k'agathós", "todo o real é verdadeiro, bom e belo". Ora, o caráter absoluto da Consolação toca no seu extremo: na dessensibilização da crueldade e da paciência, porque todo o mal participa no desenvolvimento do Melhor! A beatificação a priori dos futuros contingentes é um jogo lógico que pode alienar os jogadores.

\section{FulguraÇáo E TEMPo}

Verificamos que Leibniz, não obstante ser o filósofo da dinâmica autónoma e imanente, ou o protobiofísico da vis insita, procede, na esfera dos futuros contingentes, a uma implosão do tempo na Eternidade, do Real na Ideia Geratriz, e do Possível na não-contradição. Ora, onde se perdeu a inventividade da duraçáo? Onde se neutralizou o poder da realidade que transborda toda a ideação possível? Onde se desativou o possível-mais-doque-possível, o Potencial, que é a alma da Dinâmica fulgurante? Foi no ângulo alucinatório da omnisciência e da omnipotência que transforma o Universo, animado ou inanimado, num fenómeno lógico de "autoverificação" e num 
fenómeno ontológico de "autodesenvolvimento com autoconservação". Em Leibniz, a pré-determinação das verdades contingentes é consonante com o pré-formismo: a existência cumpre essências cuja compossibilidade as tornou eleitas. Esse essencialismo transforma as existências em meros "autodesdobramentos" com metamorfoses pré-figuradas em "disposiçôes" ou "sementes" incapazes de irrupçôes qualitativas (DELEUZE, 1988). Os futuros contingentes são análogos na história natural e na história civil, sintetizando pré-determinação com pré-formação. Só Deus pode, no princípio de tudo, produzir "fulguraçóes" e, por conseguinte, o poder inventivo do Real, a se ipso, limita-se à metamorfose pré-figurada (as aparentes geraçóes e mortes, no seio do processo vital, seriam apenas mudanças nas escalas teatrais em que a vida se manifesta). Na sua reflexão biológica, integrada nos Princípios da natureza e da graça (\$. 6), Leibniz (GP VI, p. 601) explica:

[...] les vivants dont les organes nous sont connus, c'est-à-dire les plantes et les animaux, ne viennent point d'une putréfaction ou d'un chaos, comme les anciens ont cru, mais de semences préformées, et par conséquent de la transformation des vivants préexistants. [...] Ainsi non seulement les âmes, mais les animaux sont ingénérables et impérissables: ils ne sont que développés, enveloppés, revêtus, dépouillés, transformés; les âmes ne quittent jamais tout leur corps, et ne passent point d'un corps dans un autre corps qui leur soit entièrement nouveau. Il n'y a donc point de métempsychose, mais il y a métamorphose.

A abertura radical do futuro convida ao primado da força autofulgurante sobre a ideia, ao invés da restrição das fulguraçôes existenciais ao domínio do Poder Absoluto. A convicção da abertura do futuro aceita um novo tipo de ininteligibilidade, não aquela que exprime a ignorância (complacente) dos Desígnios Superiores, mas uma outra que, desconhecendo uma ontologia das essências, descreve o processo livre das existências, onde as probabilidades condicionais nunca são plenamente computáveis. De facto, se, numa teodiceia essencialista, as fulguraçóes radicais transcendem e precedem a natureza, sendo injeçóes gratuitas, sobrenaturais, que preenchem com acréscimos de Ser o Máximo de Ser; então, simetricamente, numa ontodiceia existencialista, cada instante é um ponto saturado pela convergência caótica e pela co-tangência aleatória de potenciais livres que intensificam, sem estimativa certa, o caos e os 
alea. E, no entanto, emergem morfologias e regularidades, como se o jogo criasse e recriasse continuamente as suas regras, durante o seu próprio processo lúdico ${ }^{13}$.

Nessa ontologia do acontecimento incomputável, a ficção do Calculador Infinito torna-se uma ficção ineficaz, porque "teoricamente incrível" e "praticamente (ou moralmente) cruel". Deus, se existir, terá certamente abdicado (à luz da espontaneidade das forças autopoiéticas e da gravidade agónica do Bem e do Mal) da omnipotência e da omnisciência, autolimitando-se livremente ${ }^{14} \mathrm{e}$ assumindo uma ignorância voluntária e invencível sobre a saturação potencial dos instantes e das suas conexốes. Essa renúncia divina à omniciência/potência tem também um fundamento lógico, pois uma omniciência/potência absoluta é autocontraditória, exceto na ficção de um Deus solitário, sem criação. Todavia, na própria lógica da ficção criacionista, não seria mais "crível" e "amável" um Deus que, ao criar, se decide retirar da Criação e se autodelimita, recusando ser tudo em tudo? Se não, como poderá um "crente" justificar o Seu mutismo e a Sua apatia perante as tragédias contingentemente necessárias da história? E, mais profundamente, como justificar a sua passagem à Açáo Criadora material, que se submete ao "mal físico" da matéria (em vez de criar uma comunidade espiritual absolutamente santa)? Também Deus sofreria de cosmoagnosia e de autoagnosia, incapacidade de reconhecer a trama completa do processo de autorrealização da natureza e de Se reconhecer plenamente a Si Próprio como pensamento e ato primitivo desse processo.

O real compreende-se e descompreende-se na sua automobilidade. No vértice de cada instante, que liga e desliga o passado ao futuro, há continuidade e descontinuidade, sentido e não-sentido, em múltiplas escalas. A essência não precede inteiramente a existência: as essências convertem-se processos sem ponto-Omega, dinâmicas morfogenéticas indeterminadas que produzem incertamente constelaçôes efémeras, onde o aleatório e o regular se interpenetram e se interconstituem. A lógica do possível é, dessa forma, intensificada por uma ontologia dos mundos potenciais com espontaneidade policrónica irredutível à Graça do princípio ou ao Bem superior do eschaton. Ontologicamente, a abertura do futuro requer que tudo esteja sempre em jogo em cada instante.

\footnotetext{
${ }^{13}$ Nesta sugestão ontológica, ecoa, em parte, o indeterminismo da "ontologia do jogo ideal" de G. Deleuze (1969, p. 75-76) que postula: $1^{\circ}$ a inexistência de regras prévias (cada instante/jogada inventando as suas regras); $2^{\circ}$ a afirmaçấo e a ramificação do acaso em cada jogada, $3^{\circ}$ cada lançamento de dados como fragmento de um único lançar, ontologicamente uno, $4^{\circ} \mathrm{o}$ jogo ideal como realidade pura do pensamento e como pensamento do non-sens (sem jogador divino nem humano).

${ }^{14}$ Sob um plano mais ético-histórico do que ontológico, é esta a posiçẫo provocadoramente heterodoxa de Jonas (1994).
} 


\section{Conclusấo: Outro Deus, outra Lógica}

A incomputabilidade da autopoiética do instante pode ser inviolável. Nesse "Acontecimento-Catástrofe" do instante, pode concentrar-se a infinita arborescência (mais do que bifurcação) dos potenciais e dos condicionais sob o signo do Singular emergente. Contudo, tal ideia da concentração de todos os mundos possíveis com sua infinita policronia e sua completa pancronia, na célula catastrófica e caótica do instante, é ainda uma fiç̧ão metalógica que a nossa autodisciplina agnóstica deve moderar, em nome do ininteligível material, porque o futuro náo está necessariamente todo contido no presente. O Futuro, na sua verdade contingente, seria a possibilidade mais-do-que-lógica de outro modo de ser e nâo-ser. Por isso, a libertação da bivalência lógica salvaguarda a verdade e a espontaneidade do Real, embora metamorfoseando a verdade em operação de amplitude transcontraditória, Deus em autoagnóstico livre, e a matéria em processo inventivo. Merece ser enfatizada a índole libertadora da lógica polivalente, tal como o seu fundador, Jan Lukawiesicz a concebe: projeto científico e experiencial para fazer explodir o confinamento mental da polaridade verdadeiro/falso ${ }^{15}$ (inspirando-se na revolução das geometrias hiperbólicas, elípticas ou não-euclidianas de J. Bolyai, N. Lobachevski e B. Riemann):

To me, personally, the principle of bivalence does not appear to be selfevident. Therefore, I am entitled not to recognize it, and to accept the view that besides truth and falsehood exist other truth-values, including at least the third truth-value.

What is this third-value? [...] I maintain that there are propositions which are neither true nor false but indeterminate. All sentences about future facts which are not yet decided belong to this category. Such sentences are neither true nor false at present moment, for they have no real correlate. If we make use of philosophical terminology which is not particularly

\footnotetext{
${ }^{15}$ A este propósito, eis uma das passagens mais emotivas e autobiográficas de Lukasiewicz: "I have declared a spiritual war upon all coercition that restricts man's creative activity. There are two kinds of coercion. One of them is physical [...]. The other kind of coercion is logical. [...] This coercion is much stronger than the physical; there is no hope for liberation. No physical or intellectual force can overcome the principles of logic and mathematics. That coercion originated with the rise of Aristotelian logic and Euclidean geometry. The concept was born of science as a system of principle and theorems connected by logical relationship. [...] In the universe conceived in this way there is no place for a creative act resulting not from a law but from a spontaneous impulse [...]. A brave individual, conscious of his value, does not want to be just a link in the chain of cause, but wants himself affect the course of events. [...] He has two paths to choose from: either to submerge himself in skepticism and abandon research, or to come to grips with the concept of science based on Aristotelian logic. I have chosen that second path. In striving to transform the concept of science based on Aristotelian logic I had to forge weapons stronger than that logic. It was symbolic logic that became such a weapon for me" (LUKASIEWICZ, 1970, p. 84-85).
} 
clear, we could say that ontologically what corresponds to these sentences is neither being nor non-being but possibility. Indeterminate sentences, which ontologically have possibility as their correlate, take the third value.

[...] Whatever form, when worked out in detail, this new logic assumes, the thesis of determinism will be no part of it. (LUKASIEWICZ, 1970, p. 126)

A lógica polivalente liberta a potência da possibilidade face ao determinismo lógico, desafiando a normatividade do pensamento, sem sucumbir numa indeterminação irresolúvel (PRIEST, 2002). A verdade deve, então, entrar na trama do tempo (PRIOR, 1967) e ancorar-se nas relações contextualizadas de produção e avaliação do verdadeiro, em consonância com o princípio "pós-semântico" da relatividade e da estruturação contextual da verdade (MACFARLANE, 2003, 2008). Portanto, polivalência, temporalidade, perspetiva epistémica e performance (inter)locutória conjugam-se para libertar a instável verdade do possível que acompanha a epigénese aberta do futuro. A lógica do possível, enquanto futuro contingente, estimula uma "forma de vida", configurando uma "persona estética e ética" que evoca o enigmático homem sem qualidades, definindo-se, indeterminadamente, pelo "sentido do possível”, isto é, a "[...] capacidade de pensar tudo o que também poderia ser e de não conceder mais importância ao que é do que ao que não é", que transporta consigo uma "disposição criadora" e desestabilizadora, porque "[...] pode fazer ver a falsidade do que é admirado pelos homens ou a licitude do que é interdito por eles, ou a indiferença de ambos..." (MUSIL, 1995, p. 20). Com essa disposição criadora, a enunciação e a avaliação da verdade dos futuros contingentes abrem-se a todos os possíveis: 1. um futuro contingente é "agora" ou verdadeiro ou falso, se e só se fosse plenamente computável a ligação entre "agora" e esse "futuro"; 2. um futuro contingente não é verdadeiro nem falso, em caso de incomputabilidade relativa ou absoluta da conexáo entre presente e futuro; 3. um futuro contingente pose ser verdadeiro-e-falso, se for concebível a incoincidência lógica entre duas perspetivas qualitativamente diferenciadoras do sentido do futuro; 4. um futuro contingente pode ser ou-verdadeiro-oufalso, num regime de alternâncias qualitativas (aleatórias ou regulares) da potência do "acontecer". A crença na abertura do futuro (crença epistemicamente opaca, eticamente motivadora e ontologicamente criativa) permite um movimento lógico, espontâneo, sensivvel às condiçóes mutáveis dos operadores veritativos, circulando sem estação preferencial entre: $S$ é $P$; $S$ é não $P$; $S$ é ambos $P$ e não- $P$; $S$ não é $P$ nem não- $P$. 
JESUS, Paulo Renato. The intelligence of contingent futures: asking Leibniz about God and truth. Trans/form/ação, Marília, v. 39, n. 1, p. 9-36, Jan./Mar., 2016.

\begin{abstract}
This paper investigates the theological essence of contingent futures. First, it analyses the argument according to which, under certain logical, theological, ontological, and cosmological conditions detected by Leibniz (who reconciles St. Augustine's position with L. Molina's and W. Ockham's), the contingent openness of the future may be compatible with the regime of "predetermined contingent truths", theologically grounded in the principle of an "optimal future" or a "single true future". However, the examination of contingent futures has also fostered, both for and against Aristotle's position, the development of a many-valued and temporal logic as proposed by J. Łukasiewicz or A. Prior. This logic safeguards the openness of future without the metaphysically expensive cost of adhering to an all-determining theo-logic. It hence follows that the critique of logical determinism seems to be more appropriate to express the post-metaphysical conditions of our present agnostic mentality. In this case, however, the openness of the future would entail a profound redefinition of the very ideas and functions of "God", "matter", "history", and "truth".
\end{abstract}

KEYWORDS: Leibniz, contingent futures, theodicy, temporality.

\title{
REFERÊNCIAS
}

ARISTOTLE. De interpretatione. In: The Complete works of Aristotle: The Revised Oxford Translation. Edited by J. Barnes. Volume one. Princeton: Princeton University Press, 1995. p. 25-38.

BERGSON, H. L'évolution créatrice, Paris: Presses Universitaires de France, 1907/1941.

CARDOSO, A. O trabalho da mediação no pensamento leibniziano. Lisboa: Colibri, 2005.

DELEUZE, G. Logique du sens. Paris: Minuit, 1969.

. Le pli: Leibniz et le baroque. Paris: Minuit, 1988.

LIVRO do Eclesiastes. In: Bíblia. Lisboa: Difusora Bíblica, 1998. p. 846-856.

GASKIN, R. The Sea Battle and the master argument: Aristotle and Diodorus Cronus on the metaphysics of the future. Berlin; New York: De Gruyter, 1995.

GAUDEMAR, M. Leibniz: de la puissance au sujet. Paris: J. Vrin, 1994.

HINTIKKA, J. Time and necessity: Studies in Aristotle's theory of modality. Oxford: Clarendon Press, 1973.

JONAS, H. Le concept de Dieu après Auschwitz. Paris: Payot, 1994.

LEIBNIZ, G. W. Die philosophischen Schriften (7 v.). (GP) Hersg. von C. I. Gerhardt, Hildesheim: Olms, 1978.

. Discours de métaphysique. In: GP IV. p. 427-463.

. Essais de Théodicée. In: GP VI. p. 1-375. 
. Remarques sur le livre de l'origine du mal. In: GP VI. p. 400-436.

. Principes de la nature et de la grâce. In: GP VI. p. 598-606.

. Monadologie. In: GP VI. p. 607-623.

. De rerum originatione radicali. In: GP VII. p. 302-308.

LUKASIEWICZ, J. Selected works. Amsterdam: North Holland, 1970.

MACFARLANE, J. Future contingents and relative truth. The Philosophical Quarterly, v. 53, n. 212, 2003, p. 321-336.

Truth in the Garden of Forking Paths. In: GARCIA-CARPINTERO, M.; KÖLBEL, M. (Ed.). Relative truth. Oxford: Oxford University Press, 2008. p. 81-102.

MENDONÇA, M. A doutrina das modalidades na filosofia de G. W. Leibniz. 1999. 645f. Tese (Doutorado em Filosofia) - FCSH, Universidade Nova de Lisboa, Lisboa, 1999. Disponível em: http://dited.bn.pt/31418/2405/2916.pdf. Acesso em: 10 out. 2015.

MOLINA, L. On Divine Foreknowledge: de liberi arbitri cum gratiae donis, divina praescientia, providentia, praedestinatione et reprobatione concordia, 1588. Ithaca: Cornell University Press, 1988.

MUSIL, R. L’homme sans qualités. Paris: Seuil, 1995.

OCKHAM, W. Predestination, God's Foreknowledge, and Future Contingents. Tradução de M.M. Adams e N. Kretzmann. Indianapolis: Hackett, 1983.

ORIO, B. Leibniz: crítica de la razón simbólica. Granada: Comares, 2011.

PRIEST, G. Beyond the limits of Thought. Oxford: Oxford University Press, 2002.

PRIOR, A. N. Past, present and future. Oxford: Clarendon Press, 1967.

RAUZY, J.-B. La doctrine leibnizienne de la vérité: aspects logiques et ontologiques. Paris: Vrin, 2001.

VUILLEMIN, J. Le chapitre IX du De Interpretatione d'Aristote: vers une réhabilitation de l'opinion comme connaissance probable des choses contingentes. Philosophiques, v. X, n. 1 , p. $15-52$, avril 1983 .

Recebido em 02/11/2015

Aceito em 28/12/2015 
JESUS, P. R. 